\title{
A SVD Analysis between the Winter NH 500-hPa Height and
}

\section{Surface Temperature Fields}

\author{
By Hiroshi Koide and Kunihiko Kodera \\ Meteorological Research Institute, Tsukuba, Ibaraki, 305-0052 Japan \\ (Manuscript received 17 July 1998, in revised form 5 November 1998)
}

\begin{abstract}
A singular value decomposition (SVD) analysis between the Northern Hemisphere winter-mean 500$\mathrm{hPa}$ geopotential height (Z500) and near-global surface temperature (land-surface air temperature + sea surface temperature) fields was conducted for the recent three decades. The leading mode, referred to as Polar/Eurasia (PEA), is considered as a hemispheric-wide atmospheric internal variability rather than a local teleconnection pattern. Winter mean Z500 of the leading mode is closely related to Eurasian surface air temperature from autumn to spring throughout the period. Both interannual and interdecadal time scales are dominant during the three decades in the time scales. No linear relationship between the tropical SST anomalies is found in this mode. The second and third modes can be identified as the Pacific/North American (PNA) and Western Pacific (WP)-type teleconnection patterns, respectively. Although they are also considered as internal modes of atmospheric variabilities, their interannual variabilities are also influenced by the tropical Pacific SST anomalies. These results are compared with the more popular SVD analysis between geopotential height and SST, for which the leading mode exhibits the so-called "ENSO (El Niño/Southern Oscillation) related" winter circulation pattern. It is shown that this ENSO-related mode can be reconstructed from the linear combination of the second (PNA) and third (WP) modes of the present SVD mentioned above. These results suggest that inter-El Niño differences of atmospheric circulation in midlatitudes can be interpreted as the different strengths of the PNA and WP patterns on one hand, and on the other hand by the different magnitude of the PEA, which is linearly independent of ENSO. The characteristics of the vertical structure of the atmospheric variability were further examined by conducting a SVD analysis of 100-hPa temperature and Z500. The PEA and PNA patterns in the Z500 field extracted as the first and second SVD modes, respectively, exhibit contrasting features in association with lower stratospheric temperature. The PNA pattern is confined to the troposphere, while PEA extends further into the stratosphere. This suggests they are produced by different mechanisms.
\end{abstract}

\section{Introduction}

The impact of equatorial sea surface temperature (SST) variations on midlatitude atmospheric circulation, especially those related with the El Niño/Southern Oscillation (ENSO) cycle, has been studied using general circulation models (Lau and Nath, 1994; Kumar and Hoerling, 1997) as well as observational data (Bjerknes, 1969; Horel and Wallace, 1981). Also, studies of the influence of midlatitude SST as well as tropical SST of decadal time scale are now in progress (Nitta and Yamada, 1989; Trenberth and Hurrell, 1994; Yukimoto et al., 1996).

Corresponding author: Hiroshi Koide, Climate Research Dept., Meteorological Research Institute, 1-1 Nagamine, Tsukuba, Ibaraki 305-0052, Japan. E-mail: hkoide@mrijma.go.jp; kodera@mri-jma.go.jp

(C) 1999, Meteorological Society of Japan
In these studies, in order to extract atmospheric variability related to SSTs, singular value decomposition (SVD) analysis (Bretherton et al., 1992) is commonly used (Wallace et al., 1992), with other methods such as simple correlation with a SST index (Horel and Wallace, 1981) or canonical correlation analysis (Graham, 1994).

In their previous study, Koide and Kodera (1997) conducted a SVD analysis between the winter mean $500-\mathrm{hPa}$ geopotential height (Z500) north of $20 \mathrm{~N}$, and the near-global SST field north of 30S. They separated two distinct variabilities; one related to the ENSO cycle, and the other considered to be an internal mode of the winter atmosphere that is connected to the lower stratospheric polar vortex. In this analysis, ENSO-related variability is extracted as the leading SVD mode. However, it has been 
shown that different midlatitude circulation patterns are concerned with the ENSO cycle (Horel and Wallace, 1981; Livezey and Mo, 1987). Kodera (1998) showed that ENSO-related atmospheric variability, as represented by correlation with equatorial eastern Pacific SSTs, can be reconstructed with Pacific/North American (PNA) and Western Pacific. (WP) type circulation patterns (Wallace and Gutzler, 1981) extracted as two leading modes of regional EOFs.

By applying SVD analysis between the SST and geopotential height data (SST-SVD), it is evident that the ENSO-related mode is extracted as the leading mode. This is because the major variability in SSTs is contained in the ENSO cycle, which also occupies a large tropical area. In this case, SVD analysis becomes somewhat similar to a correlation analysis with eastern Pacific mean SSTs.

In the present SVD analysis, in addition to the SSTs, land surface air temperature is included, in order to introduce much more variability related to the midlatitude atmospheric circulation, and create a rather contrasting situation with a preceding analysis by Koide and Kodera (1997). As will be shown later, the ENSO-related mode is not extracted as a single mode, although the above-mentioned atmospheric internal mode is still separated as an independent mode. A comparison with SVD using only SST data is made. In the previous study, lag correlations with SVD expansion coefficients are calculated to get insight into a causal relationship, whether the atmosphere forces the ocean or is forced by the ocean. For the same purpose, a multiple SVD analysis is adopted in this study, in which multiple seasons of temperature fields are combined.

In the previous study of SVD analysis between $500-\mathrm{hPa}$ and $50-\mathrm{hPa}$ geopotential heights, it was shown that the internal mode of variability separated as the second mode of Z500-SST SVD, is connected to the strength of the lower stratospheric polar vortex (Koide and Kodera, 1997). Geopotential height data at $50-\mathrm{hPa}$ are convenient to investigate lower stratospheric circulation, because the horizontal derivative of height produces geostrophic wind. However, 50-hPa height roughly represents the underlying atmospheric mean temperature, including the troposphere. Therefore in this study, the $100-\mathrm{hPa}$ temperature (T100) field is investigated for additional information about the different vertical structures in the SVD modes.

\section{Data and method}

\subsection{Data}

The monthly mean Z500 data used in this study originate from the U.S. National Center for Environmental Prediction (formerly NMC). Data are presented at $5 \times 5$ latitude-longitude grid points north of $20 \mathrm{~N}$. The monthly mean T100 data analyzed by the stratosphere research group at the University of Berlin are presented at $10 \times 10$ latitude-longitude grid points north of $10 \mathrm{~N}$. For atmospheric data, winter (DJF) mean data are calculated north of $20 \mathrm{~N}$. We also use surface temperature data compiled by Dr. P.D. Jones at the University of East Anglia, U.K. In this data set, monthly mean surface air temperature (TS) anomalies over land, and SST anomalies over the oceans are merged into one data set and presented on a $5 \times 5$ latitude and longitude grid (Parker et al., 1994; Parker et al., 1995). Seasonal mean data are calculated from 3-monthly mean data for autumn (SON), winter (DJF), and spring (MAM). However, if at least one- month anomalies exist in a season, their average is treated as a seasonal anomaly. At grid points where the SST data are missing for 3 months, GISST2.2 data (Parker et al., 1995) compiled by the U.K. Meteorological Office are substituted. The distribution of grid points adopted for TS/SST data are indicated in Fig. 1. Areas south of $30 \mathrm{~S}$ are omitted because of their very small correlation with $\mathrm{NH}$ climate.

For the present study, the analysis periods are from $1963 / 64$ to $1993 / 94$, a total of 31 winters (DJF average) for all data except for T100 (T100 is available after January 1964).

\subsection{Method}

To extract predominant modes of variability that fluctuate coherently in the two data fields, a SVD analysis is widely used (Bretherton et al., 1992; Wallace et al., 1992). This method is similar to the ordinary EOF analysis, except that a crosscovariance or correlation matrix between two different data fields is used. We use a new method to calculate SVD (Kuroda, 1998), which makes use of temporal covariance rather than spatial crosscovariance to reduce matrix size and calculation time. To take latitudinal differences in grid size into account, all variables are weighted by a square root of the cosine latitude before the SVD calculation.

By applying SVD, two sets of normalized expansion coefficients for each data field are obtained. Associated spatial patterns are recovered from heterogeneous regression with the time series of expansion coefficients. In this study, spatial patterns are usually shown as heterogeneous regression maps with contours. On the same figure, to give an indication of the statistical significance, heterogeneous correlation is also indicated and absolute correlation coefficients higher than 0.4 are shaded. If the 31 years of data are independent of each other, the correlation coefficient corresponding to the $95 \%$ (99\%) confidence level is 0.355 (0.456). Expansion coefficients are displayed after normalization by standard deviations. The Squared Covariance Fraction (SCF), indicating a portion of squared cross-covariance explained by a SVD mode, is a measure of the mag- 
(a) SON

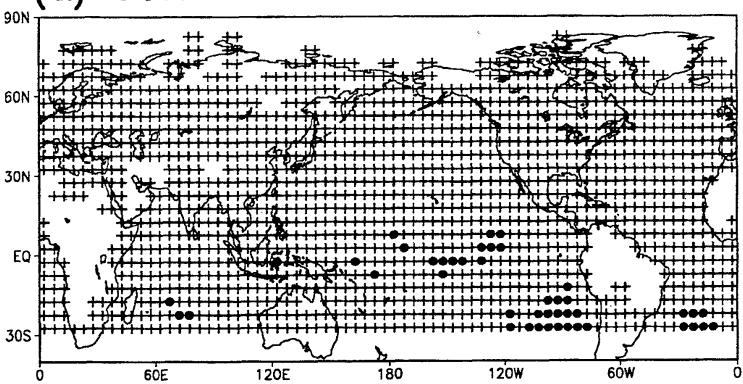

(b) DJF

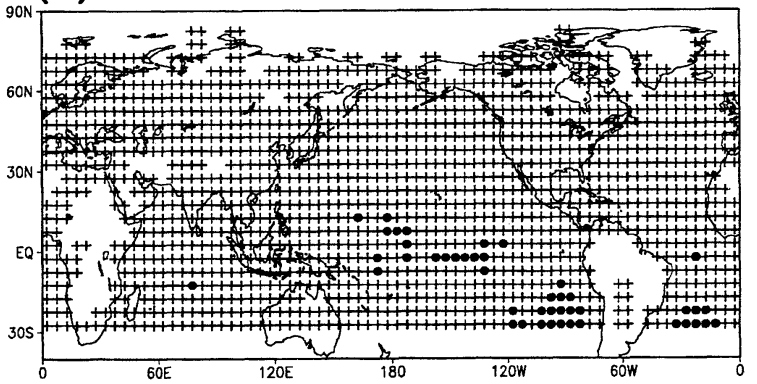

(c) MAM

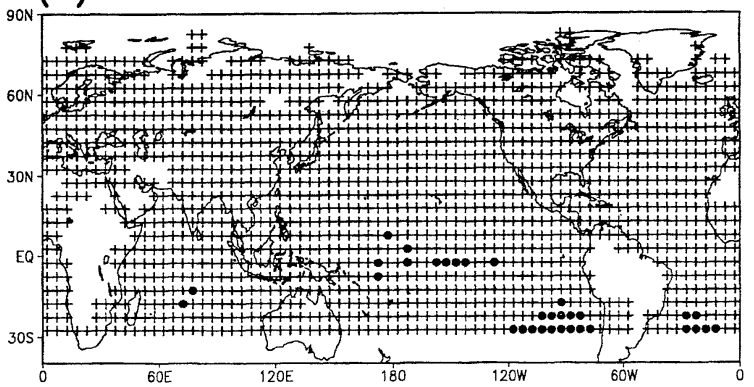

Fig. 1. The distribution of grid boxes of seasonal land surface air temperature + SST anomaly used in the present study: (a) SON, (b) DJF, and (c) MAM. Crosses and solid circles indicate Jones's dataset and GISST2.2 data, respectively.

nitude of a SVD mode. A temporal correlation coefficient between the expansion coefficients of two fields of a given SVD mode indicates how well the two fields are correlated. The average of squared heterogeneous correlation coefficients is called the Variance Fraction (VARF). VARF is used to measure how much of the total variance in a given unilateral field is explained by a SVD mode. To understand the causal relationship between the two fields, we employ a multiple SVD analysis which includes lagged relationships. In the multi-SVD analysis applied here, data fields of the different periods (for example SON, DJF, and MAM means) are compounded in a field. For example, left $(\boldsymbol{S})$ and right $(Z)$ fields are defined as follows,

$$
\left.\begin{array}{l}
\boldsymbol{S}=\left(s_{S O N}, s_{D J F}, s_{M A M}\right) \\
\boldsymbol{Z}=z_{D J F}
\end{array}\right\}
$$

Where $\mathrm{Z}$ is DJF mean Z500 anomaly field, and $s_{S O N}, s_{D J F}$, and $s_{M A M}$ are autumn, winter, and spring mean TS/SST anomaly fields. The crosscovariance matrix $C_{S Z}$ of the two fields has $3 N_{S} \times$ $N_{Z}$ elements, where $N_{S}$ and $N_{Z}$ are the number of grid points in the left and right fields (e.g., Bretherton et al., 1992).

$$
\begin{aligned}
C_{S Z} & =\left\langle\boldsymbol{S}(t) \boldsymbol{Z}^{T}(t)\right\rangle \\
& =\left\langle\left\{\boldsymbol{s}_{S O N}(t), \boldsymbol{s}_{D J F}(t), \boldsymbol{s}_{M A M}(t)\right\} \boldsymbol{z}_{D J F}{ }^{T}(t)\right\rangle .
\end{aligned}
$$

Then, a singular-value decomposition can be conducted as the ordinary case. The SVD analysis gives the left singular vectors $\boldsymbol{P}_{k}$ and the expansion coefficients $a_{k}(t)$ for the left field, $\boldsymbol{Q}_{k}$ and $b_{k}(t)$ for the right field, and associated singular values $\sigma_{k}$. Resulting multi-SVD modes are given by

$$
\begin{aligned}
\boldsymbol{S}(t) & =\sum_{k} \boldsymbol{a}_{k}(t) \boldsymbol{P}_{k} \\
& =\sum_{k} \boldsymbol{a}_{k}(t)\left\{\boldsymbol{p}_{S O N}, \boldsymbol{p}_{D J F}, \boldsymbol{p}_{M A N}\right\}, \\
\boldsymbol{Z}(t) & =\sum_{k} \boldsymbol{b}_{k}(t) \boldsymbol{Q}_{k}, \\
k & =1,2, \cdots, \min \left(3 N_{S}, N_{Z}\right) .
\end{aligned}
$$

Note $\boldsymbol{P}$ is decomposed to three vectors of sub period $\boldsymbol{p}$. It can be seen in Eq. (2.3) that spatial patterns of TS/SST for the preceding SON, simultaneous DJF, and following MAM are contained in the left singular vector.

Either a cross-covariance matrix, or correlation matrix can be used for a SVD analysis. In the present study, we have tried both and chosen the one that gives better temporal correlations between the two expansion coefficients of two fields of leading modes.

\section{Results}

In this section, three SVD analyses between $\mathrm{i}$ ) TS/SST and Z500, ii) SST and Z500, and iii) T100 and $\mathrm{Z} 500$, are performed. In the following they are denoted as TS- SVD, SST-SVD, and T100-SVD, respectively. For brevity, the leading SVD mode of TS-SVD is referred to as TS-1, and so forth.

\subsection{Multiple TS/SST-SVD analysis}

The relationship between the interannual variability in the Northern Hemisphere winter $500-\mathrm{hPa}$ height fields and the near-global surface temperature from autumn to spring is studied by means of multiple SVD analysis. Spatial patterns and expansion coefficients of the leading three modes are presented in Figs. 2 and 3, respectively.

The leading five modes respectively account for $51,23,8,5$, and $3 \%$ of SCFs in descending order. The first two modes have outstanding SCFs because they are associated with large-amplitude surface air 

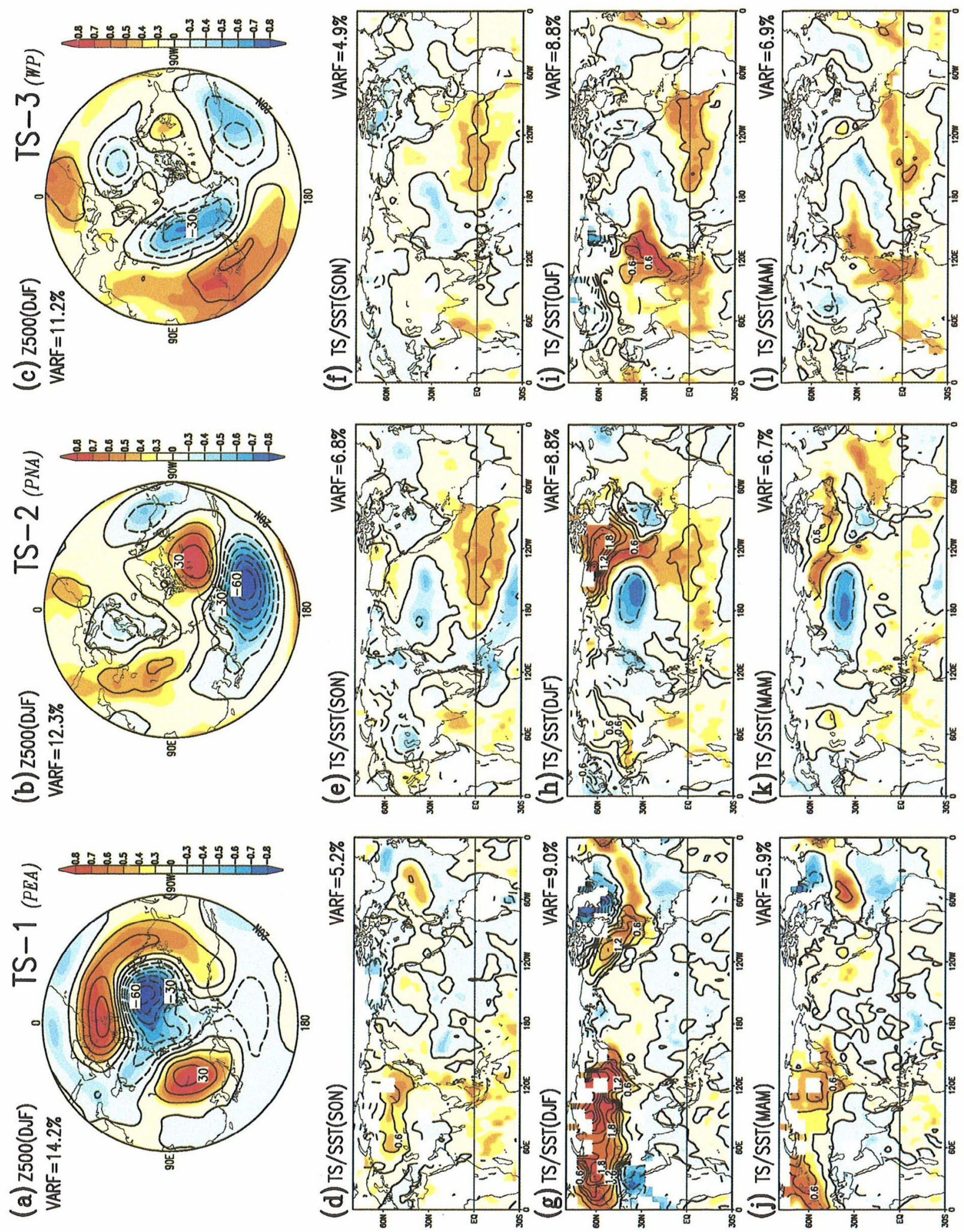

Fig. 2. Heterogeneous regression maps of SVD modes between DJF-mean 500-hPa geopotential height and multiple-season surface temperature (see text): From top to bottom, winter-(DJF) mean 500-hPa height, autumn-(SON), winter-(DJF), and spring-(MAM), mean temperature. From left to right, for the first (PEA), second (PNA), and third (WP) SVD mode, respectively. Spatial patterns of maps are obtained by regressing height and temperature anomalies at each grid points with the expansion coefficients of their counter fields. Contour interval is $10 \mathrm{~m}$ for height and $0.3 \mathrm{~K}$ for temperature. Negative contours are dashed. Color shadings indicate heterogeneous correlation coefficients. 
(a) TS-1 (PEA) $\mathrm{R}=0.949$

(b) TS-2 (PNA) $R=0.900$ (c) $\mathrm{TS}_{\text {(WP) }}$
(WP $R=0.870$

(d) SST-1 (ENSO) $R=0.812$

(e)SST-2 $R=0.900$

(f) $T S-R$ (RC ENSO) $\mathrm{R}=0.907$
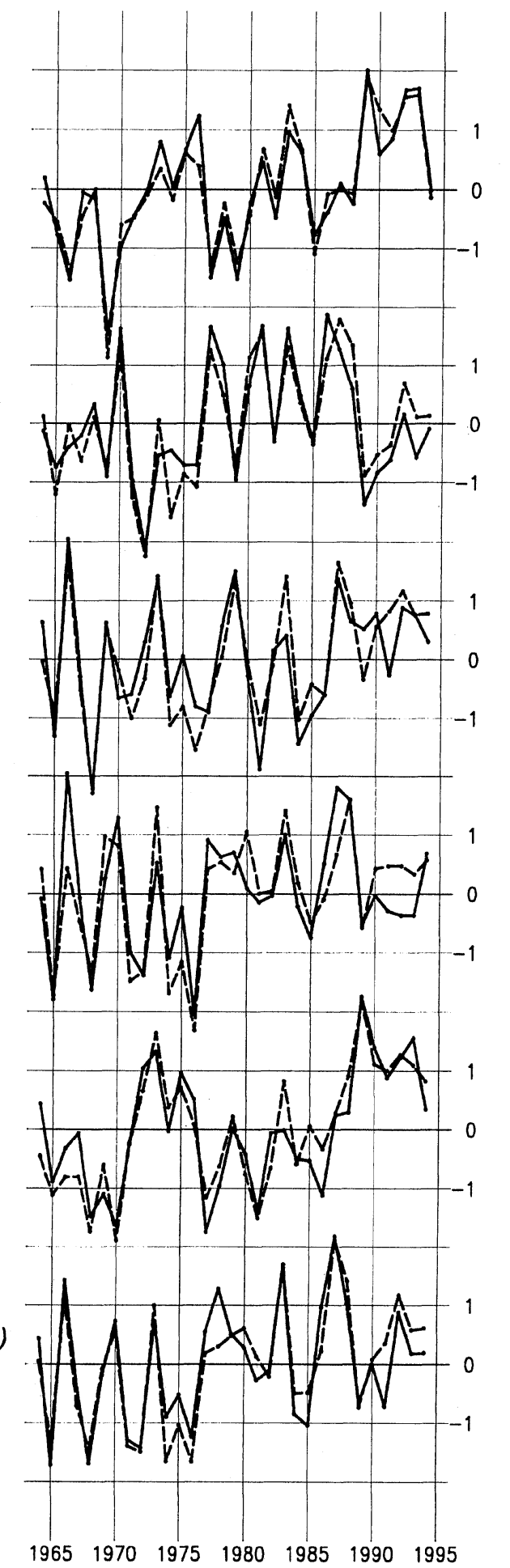

Fig. 3. Normalized expansion coefficients for the (a) first, (b) second, and (c) third SVD modes between $500-\mathrm{hPa}$ height and surface air temperature/SST fields. Normalized expansion coefficients for the (d) first and (e) second SVD modes between 500-hPa height and SST fields. (f) The same as in (a) but for the rotated SVD mode (see text). Solid and dashed lines indicate expansion coefficients of 500-hPa height and surface temperature fields, respectively. Indicated year refers to January of that winter. temperature variation coherent with the $\mathrm{Z} 500$ field over the middle- and high-latitudes. The SCF value for the third mode is lower because this mode captures surface temperature variability mainly over tropical and subtropical regions where the variability is smaller. However, VARFs of heterogeneous correlation which indicate the relative importance of variability explained by each SVD mode for a given field, is comparable for the first 3 modes. VARFs of the leading 5 modes for the Z500 field, are 14.2, 12.3, $11.2,7.4$, and $4.4 \%$, and those for DJF or winter mean TS/SST field are 9.0, 8.8, 8.8, 4.2, and $3.1 \%$. VARFs for both Z500 and TS/SST fields exhibit an apparent gap between the third and fourth modes. The cumulative SCF up to the third mode is $82 \%$. This means that about $90 \%$ of cross-covariance between Z500 in winter and TS/SST in the three seasons is explained with the three leading modes. In the present study, we concentrate our attention on these three SVD modes.

The heterogeneous regression map of Z500 of the first mode (Fig. 2a) exhibits a seesaw geopotential height between the polar region and midlatitudes. This suggests that the mode is related to the strength of the midlatitude westerly jet in the $\mathrm{NH}$ winter troposphere. The negative anomaly over the polar region is centered at southern Greenland, and positive anomalies extend from Europe to eastern North America. Positive anomalies are also found over eastern Asia around Lake Baikal. In midlatitudes, only weak negative anomalies are observed around the date line and Caspian Sea. It is also noted that the spatial structure of the regression map apparently includes a dipole- type pattern over the North Atlantic often designated as the North Atlantic Oscillation (NAO) (van Loon and Rogers, 1978; Barnston and Livesey, 1987); however, the positive anomalies over eastern Asia are by no means negligible. These anomalies give a more hemispherical structure to the Z500 map (Fig. 2a). In order to emphasize the hemispherical nature of this pattern, in the present study it is referred to as the Polar region/Europe-Asia (PEA) pattern as in Kodera et al. (1996). This is also the same pattern as that termed the Arctic Oscillation from a characteristic of the sea level pressure field (Thompson and Wallace, 1998). The heterogeneous regression map of winter mean surface temperature (Fig. 2g) shows a strong warming over the entire Eurasian and the northeastern North American continents, but cooling over the Greenland region, which is in good accordance with the above-mentioned structure of Z500. Over the Eurasian continent, a moderate warming begins in the preceding autumn over Siberia, which amplifies during the winter and persists until the following spring over Europe and East Asia. Over the oceans, a characteristic meridional tri-pole type pattern (Koide and Kodera, 1997) with 

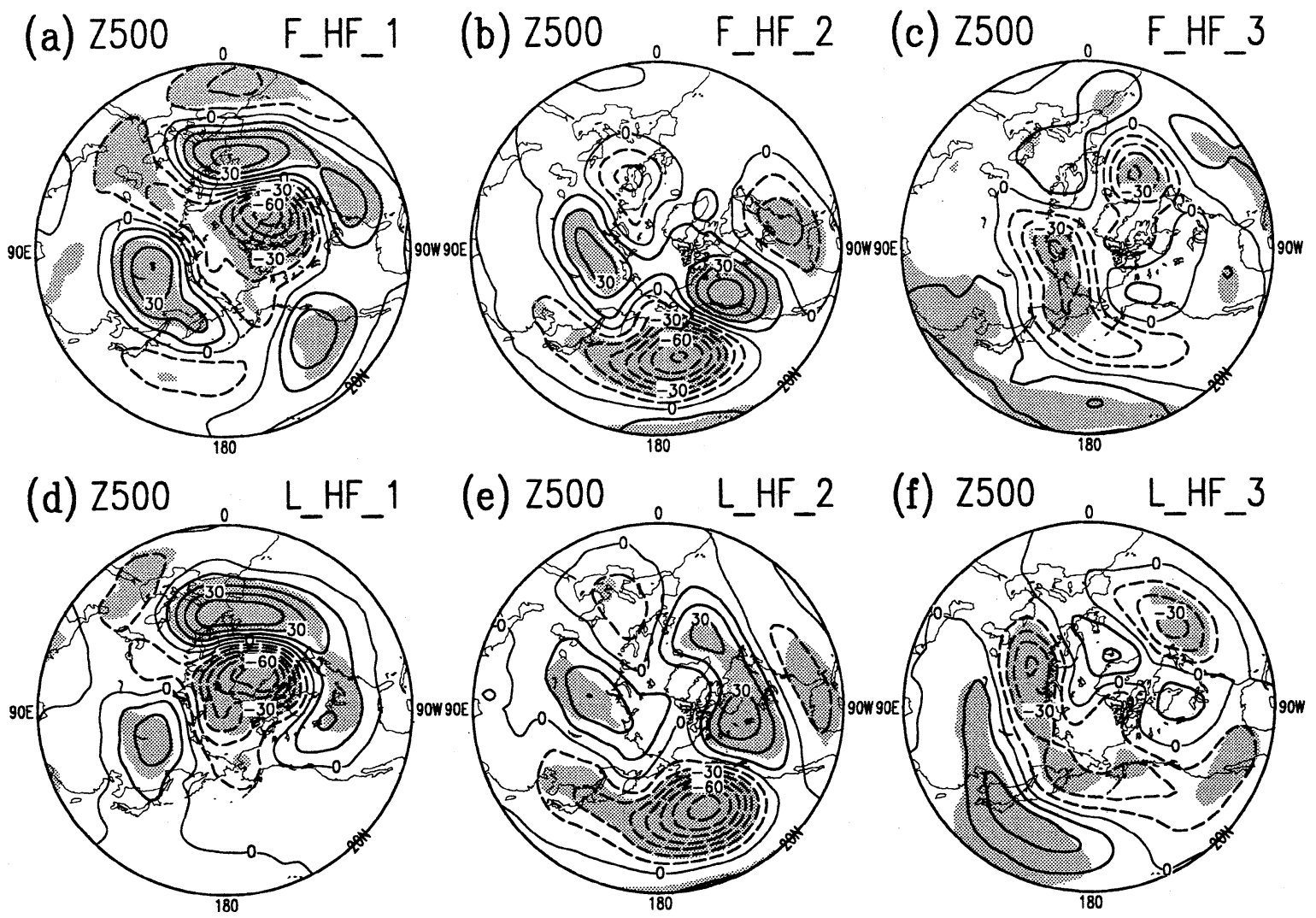

Fig. 4. The same as in the top panels in Fig. 2, but for those obtained from the first 16 years (top panels) and last 16 years (bottom panels) of the original 31-years dataset. Negative contours are dashed and zero contours are represented by thinner lines. Shadings indicate where the absolute heterogeneous correlation is greater than 0.5 .

negative anomalies north and south of a positive anomaly, is formed over the central North Atlantic according to the seasonal progression from autumn to spring (Figs. 2d, 2g, and $2 \mathrm{j}$ ). No other significant signal is observed in SST data.

Another notable feature of the first mode is found in the temporal domain. The expansion coefficients (Fig. 3a), both for the Z500 and TS/SST time series, exhibit a considerable increasing trend and decadal variability during the last three decades. A very high (0.95) correlation coefficient between the two expansion coefficients indicates a strong linkage between the mid-tropospheric atmospheric circulation and the surface temperature anomaly.

In the case of the second mode, the Z500 heterogeneous correlation map exhibits a clear PNA teleconnection pattern (Fig. 2b). Centers of action in the correlation map are found at $45 \mathrm{~N}$, $160 \mathrm{~W} ; 60 \mathrm{~N}, 110 \mathrm{~W}$; and $30 \mathrm{~N}, 75 \mathrm{~W}$, which almost perfectly coincide with the PNA index defined by Wallace and Gutzler (1981). Thus, the second mode can be identified easily as that related with PNA. The geographical distribution of surface temperature anomalies in DJF associated with the second mode shows warming over the entire North American continent except for the southeastern part, and moderate cooling over the central North Pacific (Fig. $2 \mathrm{~h}$ ). Moderate warm anomalies are also found over the equatorial Pacific. It is interesting to note that in the preceding autumn the midlatitude anomalies are very weak (Fig. 2e), whereas equatorial anomalies are even stronger than during winter. In the following spring (Fig. 2k), the extent and amplitude of the North Pacific SST signals are still comparable with those during winter, while anomalies in the tropical Pacific are no more significant. Time series of the second mode indicate that this mode involves interdecadal variability as well as interannual variation (Fig. 3b). It is noteworthy that the amplitude of the short- term variability is very high between $1976 / 77$ to $1987 / 88$ during the period when the decadal component has high positive values.

For the third mode, the heterogeneous correlation map of Z500 exhibits a distinct north-south dipole pattern extending from eastern Asia to the central Pacific. Centers of significant correlation are found around $35 \mathrm{~N}, 130-150 \mathrm{E}$ and $65 \mathrm{~N}, 100-150 \mathrm{E}$. This pattern is similar to the West Pacific (WP) teleconnection pattern defined by Wallace and Gutzler (1981), but the centers of action are located a little northwestward. For convenience this pattern is referred to as WP in the present discussion. Around 
the North American continent, a feature of Tropical/Northern Hemisphere (TNH) pattern (Mo and Livesey, 1986) is also observed but it is less significant. The surface temperature pattern of the third mode during DJF (Fig. 2i) shows a significant warming over the western North Pacific and Southeast Asia in relation to the WP teleconnection pattern. The warm anomaly also extends over a wide area from Southeast Asia to the tropical Indian Ocean, covering the entire East Asian winter monsoon region. Similar to the second mode, the third mode also shows correlations over the equatorial Pacific region. This equatorial signal already appeared in the preceding autumn (Fig. 2f), while no significant temperature signals are observed over the East Asian sector. However, in the following spring (Fig. 21), while correlation over the East Asian sector still persists, correlation of the equatorial Pacific attenuates. In the expansion coefficients of the third mode, interannual variability is more prominent (Fig. 3c). Temporal correlation between the two fields seems to be deteriorated after the end of the 1980's, and expansion coefficients tend to remain positive after the $1986 / 87$ winter.

In the present multiple SVD analysis, it was found that the variability related to the tropical SST anomalies is shared equally with the second and third modes. Although the equatorial patterns of the two modes are very similar, extratropical patterns are quite different in accordance with the difference in Z500 patterns. This result is quite different from that obtained with SVD analysis using only SSTs and Z500, in which SST variability in the equatorial eastern Pacific is represented by only one dominant mode related to the ENSO cycle. Therefore, one might suspect that in the present analysis the modes of variability related to the equatorial SSTs are not properly extracted. In order to examine the stability of the present analysis, we have conducted the same SVD analysis by dividing the total period of 31 years into two equal 16-year periods. For brevity, only heterogeneous correlation maps of Z500 are shown in Fig. 4. A visual inspection easily reveals that the leading three SVD modes calculated from the first (top panel) and last (bottom panel) 16 years of data exhibit patterns very similar to the original ones. In fact, spatial correlations between the original Z500 pattern and those of the half period exceed 0.6 in all cases, and even 0.8 , except for the third mode of the last 16-winter case. This suggests that the results of the present TS-SVD analysis are robust enough for the change of sampling period. Therefore, we consider that they reflect some physical reality.

\subsection{SST-SVD analysis}

As mentioned above, by applying the SVD analysis between the SST and Z500 fields, variability related to the ENSO cycle can be separated as the dominant mode of variability. In the present section, therefore, differences between the SST-SVD analysis are examined.

Heterogeneous regression maps for the first SVD mode of winter Z500 and SST calculated using a cross-correlation matrix are shown in Figs. 5a and $5 \mathrm{c}$. The leading mode of heterogeneous regression map for SST exhibits a strong signal over the equatorial region, whose spatial structure can be identified easily as that related to the ENSO cycle (e.g., Rasmusson and Carpenter, 1982; Halpert and Ropelewski, 1992), while the Z500 map (Fig. 5a) also shows the typical "ENSO-related atmospheric pattern" obtained by different methods - correlation, composite, SVD analysis etc. (e.g., Horel and Wallace, 1981; Lau and Nath, 1994). We can also verify that peaks of time series of this mode coincide well with the El Niño events (e.g., winters $1963 / 64,1965 / 66,1968 / 69,1969 / 70,1972 / 73$, $1976 / 77,1982 / 83,1986 / 87,1987 / 88$ and $1991 / 92$ according to the definition of the JMA) (Fig. 3d). It should also be noted that an outstanding SST signal over the tropical Pacific is found only in the first mode.

In order to illustrate the relationship between the two SVD analyses, heterogeneous regression maps of Z500 field of SST-SVD are projected onto that of TS-SVD. It should be remembered that the heterogeneous regression patterns of TS- SVD are orthogonal to each other. Figure 6 shows what portion of the spatial variability of the leading modes of the Z500 heterogeneous regression map of SSTSVD is explained by each of the first 10 modes of TS-SVD. It can be seen that the leading mode of SST-SVD is projected essentially onto two TS-SVD modes. Spatial correlation coefficients between the regression maps of Z500 of the leading mode of SSTSVD and that of second and third mode of TS-SVD are $r_{2}=0.72$ and $r_{3}=0.61$, respectively. This indicates that $90 \%$ of the variance of $\mathrm{Z} 500$ of the leading SST-SVD mode is explained by the two TSSVD mode. SST-1 can be practically reconstructed simply by a rotation in the phase space defined by TS-2 and TS-3 (Cheng and Dunkerton, 1995). In order to examine the reconstructed features of SST-1 in greater detail, new spatial patterns (rotated singular vectors) for both the TS/SST field $\left(\boldsymbol{P}_{R}\right)$ and Z500 field $\left(\boldsymbol{Q}_{R}\right)$ are calculated as follows,

$$
\begin{aligned}
& \boldsymbol{P}_{R}=\left(\boldsymbol{P}_{2} \sqrt{\sigma_{2}} \cos \theta+\boldsymbol{P}_{3} \sqrt{\sigma_{3}} \sin \theta\right) / \boldsymbol{w}_{P}, \\
& \boldsymbol{Q}_{R}=\left(\boldsymbol{Q}_{2} \sqrt{\sigma_{2}} \cos \theta+\boldsymbol{Q}_{3} \sqrt{\sigma_{3}} \sin \theta\right) / \boldsymbol{w}_{Q}
\end{aligned}
$$

where $\boldsymbol{P}_{2}, \boldsymbol{Q}_{2}$ and $\boldsymbol{P}_{3}, \boldsymbol{Q}_{3}$ are the left and right singular vectors $\left(\left|\boldsymbol{P}_{i}\right|=1,\left|\boldsymbol{Q}_{i}\right|=1\right)$ for TS-2 and TS-3 components, respectively. $\boldsymbol{w}_{P}$ and $\boldsymbol{w}_{Q}$ are constant factors to make the vector length unity. Angle of rotation $\theta$ is determined as, 
(a) $Z 500$ (DJF)

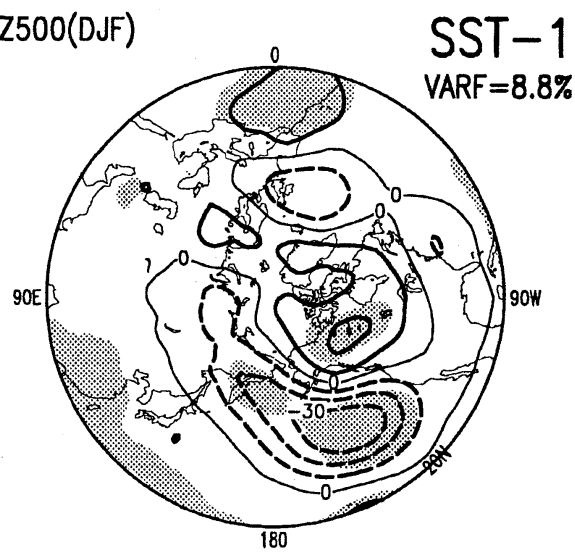

(c) SST(DJF)

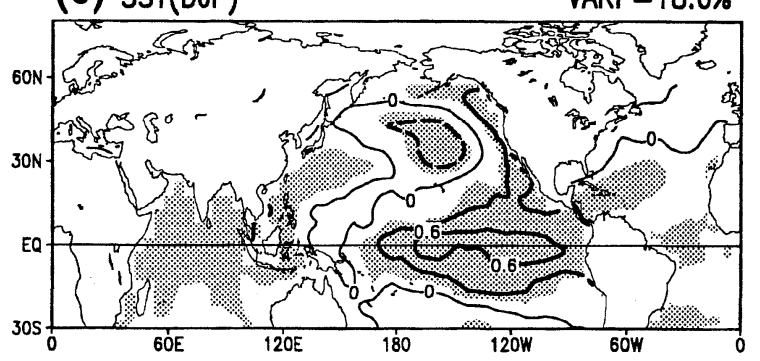

(b) Z500(DJF)

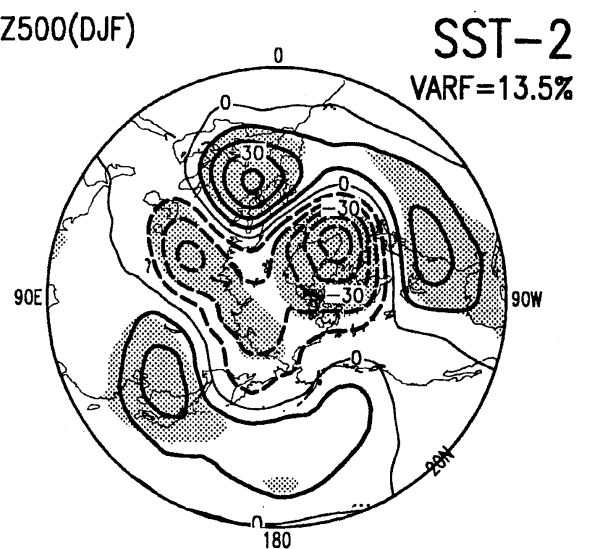

(d) $\operatorname{SST}(\mathrm{DJF})$

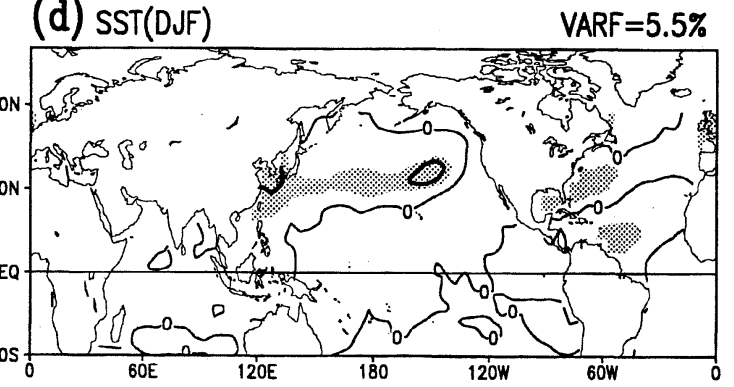

Fig. 5. The same as in Fig. 2, but for SVD modes between (top panels) winter-mean 500-hPa geopotential height and (bottom panels) winter-mean SST. The first and second modes are shown in left and right panels, respectively. Shadings indicate where the absolute heterogeneous correlation is greater than 0.4 .
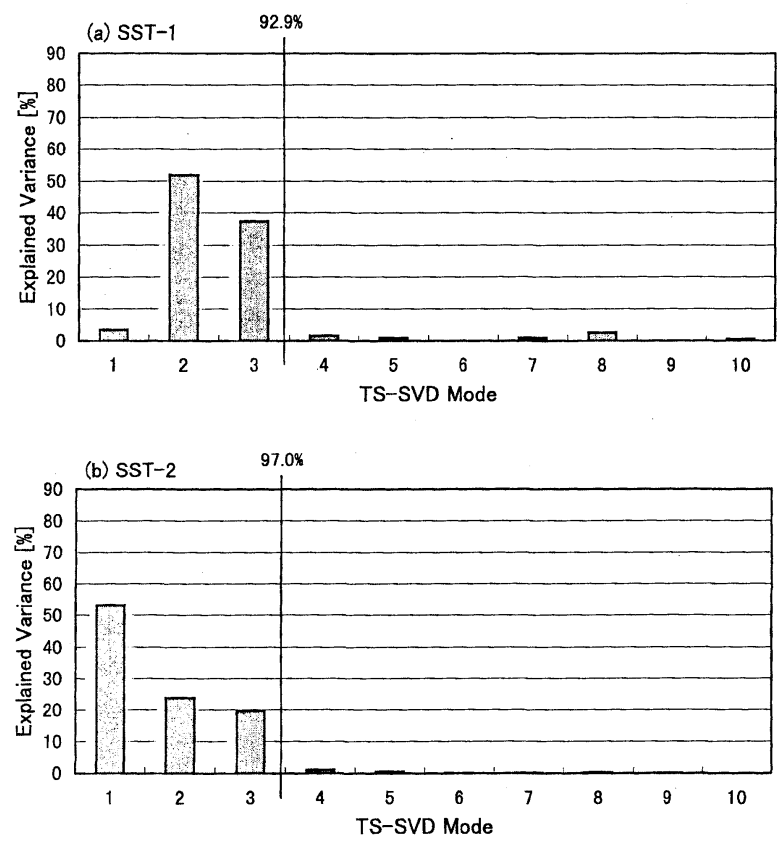

Fig. 6. (a) Percentage of the total spatial variance in $500-\mathrm{hPa}$ heterogeneous regression map for the first SVD mode of $500-\mathrm{hPa}$ height and SST projected upon the upper 10 singular vectors of SVD modes of $500-\mathrm{hPa}$ height and surface air temperature/SST. (b) As for (a) but for the second mode.

$$
\theta=\tan ^{-1}\left(\frac{r_{3}}{r_{2}} \frac{\sqrt{\sigma_{2}}}{\sqrt{\sigma_{3}}}\right)=48^{\circ} .
$$

The time series of expansion coefficients for this rotated TS-SVD (TS-R) mode are also calculated as,

$$
\begin{aligned}
\alpha_{R}(t) & =\left\{\alpha_{2}(t)\left(1 / \sqrt{\sigma_{2}}\right) \cos \theta\right. \\
& \left.+\alpha_{3}(t)\left(1 / \sqrt{\sigma_{3}}\right) \sin \theta\right\} \boldsymbol{w}_{P} \\
\beta_{R}(t) & =\left\{\beta_{2}(t)\left(1 / \sqrt{\sigma_{2}}\right) \cos \theta\right. \\
& \left.+\beta_{3}(t)\left(1 / \sqrt{\sigma_{3}}\right) \sin \theta\right\} \boldsymbol{w}_{Q}
\end{aligned}
$$

Rotated regression patterns for height and temperature according to Eqs. (3.1) and (3.2) are displayed in Figs. 7a and 7b, respectively. For brevity, only the DJF map is displayed from the three seasons of the TS/SST field. Almost perfect reconstruction of the SST-1 mode (Figs. $5 \mathrm{a}$ and $5 \mathrm{c}$ ) is obtained by the rotated two TS-SVD modes, although the SST-1 mode does not include the land-surface air temperature field. The reconstructed pattern of Z500 exhibits similar features to the PNA pattern over the eastern Pacific-American sector. However, it looks more like a WP pattern over the western Pacific-Asian sector. The spatial correlation between Z500 patterns for reconstructed TS-R (Fig. 7a) and SST-1 (Fig. 5a) is $0.95\left(=\sqrt{\boldsymbol{r}_{2}{ }^{2}+\boldsymbol{r}_{3}{ }^{2}}\right)$. The difference of Z500 patterns for SST-1 and TS-R (Fig. 
(a) 2500 (DJF)

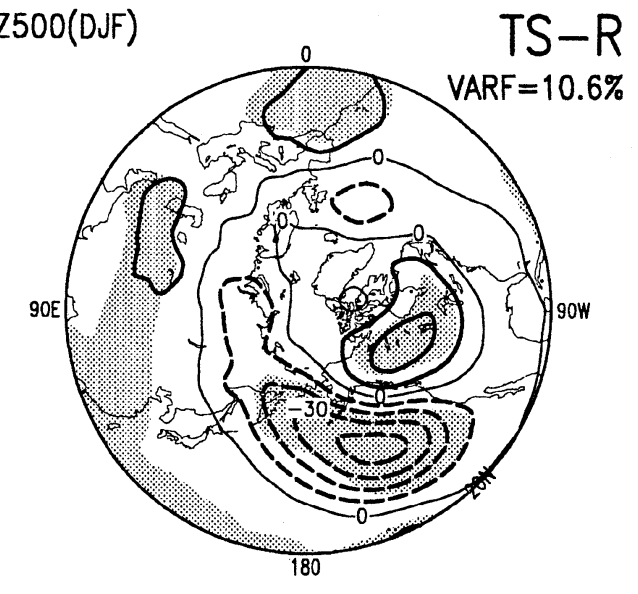

(c) TS/SST(DJF)

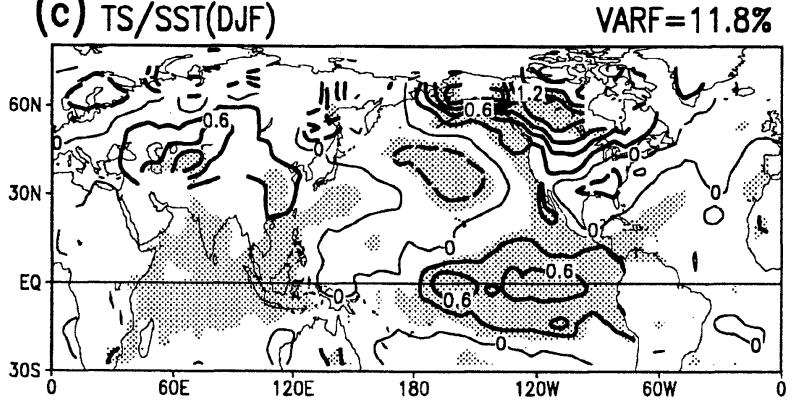

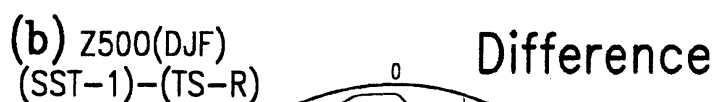

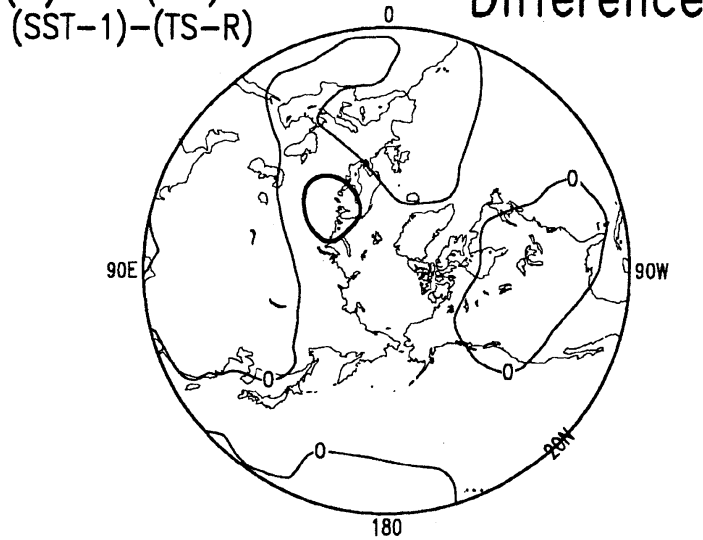

Fig. 7. The same as in Fig. 2, but for the heterogeneous regression maps for (a) 500-hPa height and (c) surface air temperature/SST of rotated SVD mode between the second and third modes in Fig. 2. (b) The difference between Fig. 5a and (a): (a) is subtracted from Fig. 5a. Contour intervals are 10 $\mathrm{m}$ for height, and $0.3 \mathrm{~K}$ for temperature fields. Shadings indicate where the absolute heterogeneous correlation is greater than 0.4 .

7c) has almost no signals, especially over the Pacific sector.

Normalized time series of rotated components defined by Eqs. (3.3) and (3.4) are indicated in Fig. 3f. Temporal correlations between the rotated TS$\mathrm{R}$ mode (Fig. 3f) and SST-1 mode (Fig. 3d) are 0.89 for both $\mathrm{Z} 500$ and temperature fields.

In contrast to the SST-1 mode, the second SSTSVD mode (SST-2) shows no significant variability in SSTs over the equatorial regions, except for the equatorial Atlantic Ocean (Fig. 5d). Some significant positive signals are found in a limited area over the midlatitude oceans around $30-40 \mathrm{~N}$, and negative signals over the subtropical North Atlantic. The spatial pattern of the Z500 map of this mode (Fig. $5 \mathrm{~b})$ resembles the first mode of TS-SVD (Fig. 2a). In fact, the Z500 map shows negative values over the polar region and positive values in midlatitudes, which resembles the PEA patterns for TS-1 (Fig. 2a). Time series of the SST-2 mode (Fig. 3e) also exhibit an increasing trend with decadal scale variability superposed (Fig. 3a). The peak in the early 1980 's is, however, weaker in the present case.

As can be seen in Fig. 6b, the major part (53\%) of the variability in the Z500 field of the SST-2 mode is principally projected onto the TS-1 mode, although a non-negligible part of the variance is still explained by TS-2 (24.0\%) and TS-3 (19.8\%). The Z500 patterns of SST-2 and TS-1 differ mainly over the central North Pacific sector. In fact, if the longitudinal zone of $150 \mathrm{E}-120 \mathrm{~W}$ is excluded, spatial correlation between the two Z500 maps improves from 0.7 to 0.8 . Therefore, we consider that these two SVD modes capture the same mode of atmospheric variability, but they are slightly distorted according to how much weight is placed over the Eurasian continent or Pacific Ocean regions in relation to the use of land-surface air temperature data. This mode of variability is considered as an internal mode of variability in the winter atmosphere extending up to the lower stratosphere (see Introduction). In the following section, to better understand this mode, the relationship with the $100-\mathrm{hPa}$ temperature field is analyzed.

\subsection{T100-SVD}

A SVD analysis based on the cross-correlation matrix between the winter mean air temperature at $100 \mathrm{hPa}$ and $\mathrm{Z} 500$ is conducted. The heterogeneous regression maps for T100 and Z500 are displayed in the upper and lower panels, respectively, of Fig. 8 . The Z500 maps for the first two leading modes of the 

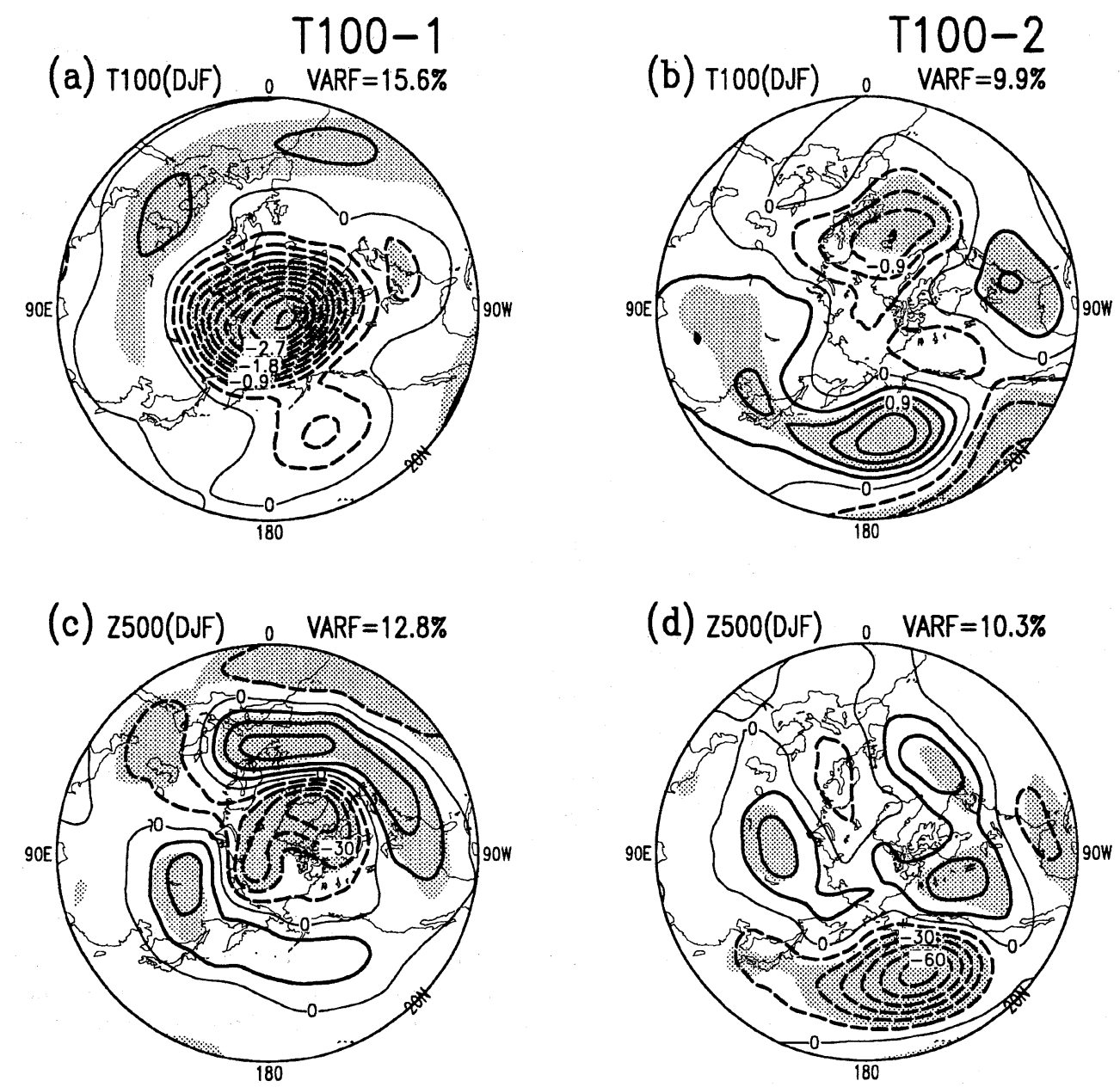

Fig. 8. The same as in Fig. 2, but for the heterogeneous regression maps of (left) the first, and (right) second SVD modes between winter-mean (top panel) $100-\mathrm{hPa}$ temperature and (bottom panel) 500-hPa height. Contour intervals are $0.3 \mathrm{~K}$ for temperature and $10 \mathrm{~m}$ for height fields. Shadings indicate where the absolute heterogeneous correlation is greater than 0.4 .

T100-SVD analysis (Figs. 8c and 8d) are very similar to those of TS-SVD (Figs. $2 \mathrm{a}$ and $2 \mathrm{~b}$ ). For a more quantitative comparison of the spatial pattern, the two leading modes of T100-SVD are projected onto the TS-SVD modes, similar to Fig. 6 . The percentages of Z500 variance explained by each of the first 10 TS-SVD modes are depicted in Fig. 9. Although a quite different single field correlated with Z500 is considered, a roughly one-to-one correspondence between the SVD modes is observed. For the first two modes, nearly $80 \%$ of the variance is explained by their counterparts, while for the third mode, the correspondence deteriorates. The explained variance is $62.5 \%$ by the leading three TS-SVD modes, so further discussion is limited to the leading two T100SVD modes.

Spatial patterns of the leading mode of T100 (Figs. $8 \mathrm{a}$ and $8 \mathrm{~b}$ ) are somewhat similar to those of Z500, with negative values over the polar region and positive values in midlatitudes. In the case of T100, however, negative regions are expanded to a lower latitude around $50 \mathrm{~N}$, and positive values over the Eurasian continent are also at a lower latitude around $40 \mathrm{~N}$. It is also noted that T100 has a more zonal structure. In the case of the second mode, the T100 map (Fig. 8b) roughly exhibits a mirror image of Z500 over the Pacific and North American regions. Most of the centers of significant correlation in the T100 map coincide approximately with the action centers of the PNA in the Z500 map, but with opposite polarity.

\section{Discussion}

In the present study, a SVD analysis between the $\mathrm{NH}$ winter $\mathrm{Z} 500$ and near-global multi-seasonal TS/SST is conducted. The spatial structure of Z500 of the leading mode of SVD exhibits a hemispherical zonally symmetric seesaw pattern between the polar region and the midlatitudes. The signal is especially strong over the polar region and Eurasian sector (PEA), which is related to large temperature changes over the Eurasian continent. Z500 spatial 

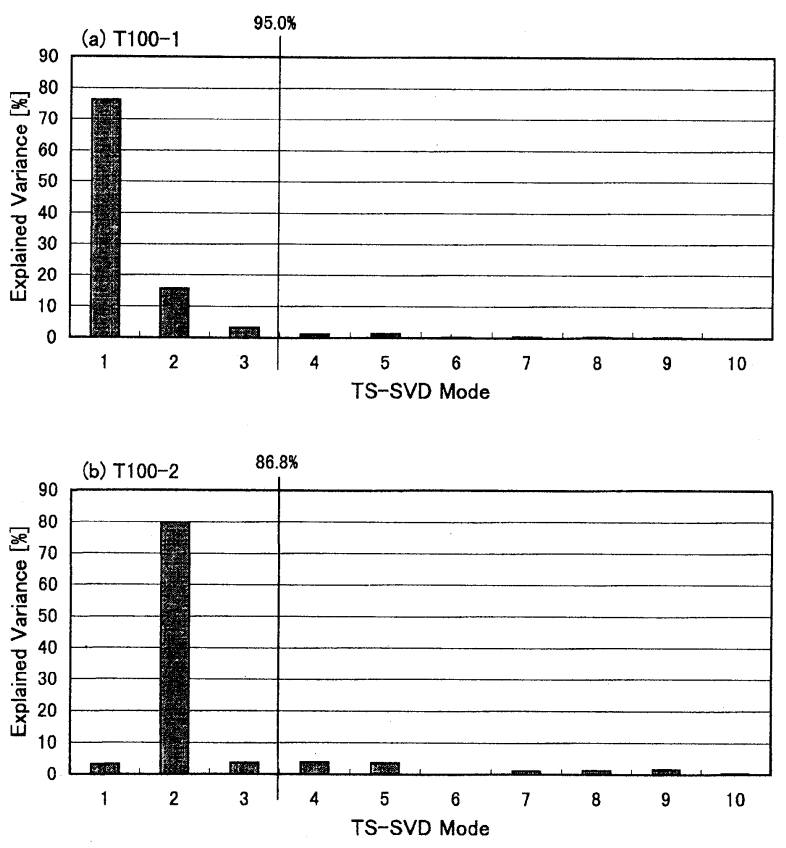

Fig. 9. As for Fig. 6, but for SVD between $100-\mathrm{hPa}$ temperature and $500-\mathrm{hPa}$ height.

patterns of the second and third modes can be identified as PNA and WP teleconnection patterns. The second and third modes show a moderate correlation with tropical Pacific SST, while the first mode has no clear relationship with tropical SSTs.

It is believed that variations in equatorial SSTs modulate the convective activity in the tropics. Atmospheric stationary waves forced by changes in diabatic heating then propagate into the extratropics, which in turn force the underling midlatitude oceans. Such a process is known as the "atmospheric bridge." In particular, the role of the atmospheric bridge over the Pacific sector by the PNAtype circulation is well documented (e.g., Nitta and Yamada, 1989; Trenberth and Hurrell, 1994; Lau and Nath, 1994; Lau and Nath, 1996). Because the present multiple SVD analysis takes into account the lagged relationship between the atmosphere and surface temperature, it is particularly convenient to study such a process.

The role of PNA as the atmospheric bridge can be seen clearly in heterogeneous regression maps (Fig. 2 ). Inspection of the evolution of SSTs from autumn to spring reveals that over the Pacific region, variations in equatorial SSTs lead the atmosphere (Fig. 2e), while underlying midlatitude SSTs lag (Figs. $2 \mathrm{~h}$ and $2 \mathrm{k}$ ). It should be noted that, in the present analysis, a 3-month lag is used to see the seasonal development while the lagged SVD analysis in the previous study showed that the typical time scale of the atmospheric bridge is about 2 months (Fig. 5 in Koide and Kodera, 1997). Although the time scale is different, the present results support the idea that warming of the equatorial Pacific is the cause of the circulation change over the Pacific region in the mid 1970's (Nitta and Yamada, 1989; Trenberth and Hurrell, 1994). However, we also need to be careful before drawing a conclusion, because another atmospheric bridge mediated by the WP pattern should exist over the Pacific region between the equatorial eastern Pacific and the South China Sea (e.g., Ose et $a l ., 1997)$. It is interesting that not only the spatial pattern, but also the time evolution of the equatorial SSTs, are quite similar between the two cases (cf. Fig. 2). This suggests that for similar variations of equatorial SSTs, the atmosphere can respond in different ways. Thus, the variability in equatorial SSTs may not be transmitted as a linear response to the midlatitudes (see also Kodera, 1998).

In the case of the Atlantic region, related to the first mode of TS-SVD, equatorial SSTs seem behind the atmospheric variability and develop simultaneously with the midlatitude anomalies (Figs. $2 \mathrm{~g}$ and $2 \mathrm{j}$ ). In autumn, except for a small region of the midlatitude North Atlantic (Fig. 2d), no significant SST anomalies are found. Over Siberia, warming is found during the period from autumn to spring. Such Siberian warming cannot be explained as a strengthening of westerlies over the Euro-Atlantic region associated with NAO (Rogers and MosleyThompson, 1995).

In contrast to the TS-SVD analysis using both the land-surface air temperature and SST data, when SVD analysis using only SST data is conducted, El Niño-related variability is extracted as the leading mode. It was also shown that the leading mode of SST-SVD is projected exclusively onto two modes of TS-SVD, the TS-2 and TS-3 modes.

Generally, a mode of variability extracted as the leading mode of SVD has a large amplitude and/or large extent. This means that large-amplitude temperature variations over the extratropical continents or coherent temperature variability over large equatorial regions tend to be selected as the leading mode, according to whether land-surface air temperature is included or not. Therefore, it is not surprising that the leading mode of SST-SVD shows a spatial pattern very similar to that obtained by the correlation analysis with equatorial SSTs over El Niño regions (e.g., Fig. 2a in Kodera, 1998). In the present study, a cross-covariance matrix is adopted for TS-SVD analysis while a cross-correlation matrix is used for SST-SVD analysis. The use of a cross-correlation matrix is equivalent to the use of normalized temperature. So this procedure emphasizes the role of large equatorial regions. If the crosscorrelation matrix is used instead of cross-covariance matrix for TS-SVD, the resultant modes become rather similar to those obtained by the SST-SVD. On the other hand, no practical difference is found 
if the cross-covariance matrix is used in SST-SVD.

The present results suggest that ENSO related SST variability is related to two different atmospheric teleconnection patterns over the North Pacific. We also demonstrated that the ENSO-related variability extracted by SST-SVD analysis can be reconstructed by a linear combination of TS- 2 and TS-3 components. These results not only confirm the results of Kodera (1998) based on two regional EOFs to reconstruct a midlatitude ENSO-related circulation pattern, but also clearly shows that there is no contribution of other SVD modes (see Fig. 6a). Because $90 \%$ of the variability in the leading SSTSVD mode can be reconstructed from two modes of TS-SVD, we may consider that the variability extracted by the two kinds of SVD analysis the same, but decomposed differently.

If we interpret the results according to the SSTSVD, there should be a specific atmospheric circulation pattern related to the equatorial SSTs, but if we adopt the results of TS-SVD, there are two atmospheric teleconnection circulation patterns. In order to examine which point of view is more realistic or physical, we may pose a question as followsFor each El Niño winter, is a similar atmospheric pattern found, or does the atmospheric circulation have a PNA-like pattern for one El Niño winter but a WP-like pattern for another?

Kodera (1998) separated nine El Niño winters from 1965 to 1994 into five PNA-type and four WPtype winters based on the regional Z500 EOF. Although the number of the events are limited, his results suggest that the ENSO-related pattern does not necessarily appear in each El Niño winter, but a more PNA or WP-like pattern appears for individual winters. In fact, it has been known that the sea level pressure pattern over the North Pacific is very different from one El Niño year to another (Emery and Hamilton, 1985), and their strong North Pacific atmospheric circulation patterns roughly correspond to the PNA-type, and weak and near-normal ones to the WP-type in the present study.

It is also noted (Fig. 3 ) that the TS-1 mode often takes the opposite sign among different El Niño winters. Concerning the inter-El Niño variability, Ting et al. (1996) showed that individual winter anomalies in 500-hPa height can be reconstructed with the two mode of variability, one related to the tropical Pacific SST index and the other to the zonal wind index. However, the present results suggest that ENSO-related variability could further be decomposed to PNA and WP modes. On the other hand, their zonal-index related mode (see Fig. 6a in Ting et al., 1996) exhibits features similar to the present PEA mode (Fig. 2a), although the zonal-index related mode includes some PNA-like features. In this respect, it may be more appropriate to consider that inter-El Niño variations mainly arise from the dif- ference in amplitudes of the three TS- SVD modes, which are the PEA, PNA, and WP patterns.

From a large number of ensemble GCM experiments, Hoerling and Kumar (1997) concluded that inter-El Niño differences at midlatitudes are attributable to atmospheric internal variability rather than the different SST forcings of each El Niño event. If this is so, the present result suggests that we need to further identify two different causes of inter-El Niño variability. One is whether the PNA or WP mode is triggered more or less strongly for each El Niño event. In other words, inter-El Niño variability is due to non-linear midlatitude atmospheric response to the equatorial forcing. The other is due to the existence of an atmospheric internal variability such as PEA, which is essentially independent of the ENSO cycle, at least from a linear point of view.

Although PNA is also an internal mode of atmospheric variability which can be produced without changes in equatorial SSTs (e.g., Zhang and Wallace, 1996; Kawamura et al., 1997), PEA has particular characteristics which differ from other teleconnection patterns. Although the PEA pattern (Fig. 2a) apparently contains the NAO pattern with dipole-type anomalies over the North Atlantic sector, PEA may be better characterized as changes in the meridional propagation of planetary waves and polar night jet (see Kodera et al., 1997).

Tropospheric teleconnection patterns such as PNA, WP, and NAO are generally considered to be maintained through interaction between the transient eddies and regional stationary waves (Lau, 1978; Rogers and Mosley-Thompson, 1995; Lin and Derome, 1997; Serreze et al., 1997). Such regionalscale tropospheric teleconnection patterns cannot propagate into the stratosphere and their amplitude declines very rapidly in the stratosphere. Therefore, the vertical gradient of geopotential height $\left(\Phi^{\prime} Z\right)$ of perturbation geopotential height $\left(\Phi^{\prime}\right)$ should have opposite sign near the tropopause region as,

$$
\Phi_{Z}^{\prime} / \Phi^{\prime}<0 \text {. }
$$

Because the vertical gradient of the height is proportional to the temperature, the above relationship indicates that regional-scale tropospheric height anomalies accompany the opposite sign of temperature anomalies in the lower stratosphere.

In fact, the spatial pattern of the T100-2 mode clearly shows that the opposite sign of temperature field is associated with the PNA pattern (Figs. 8b and $8 \mathrm{~d}$ ). This is perfectly consistent with the idea that the PNA is forced in the troposphere. However, in the case of the PEA (see Figs. $8 \mathrm{a}$ and 8c), polar temperature anomalies in the lower stratosphere have the same sign as $500 \mathrm{hPa}$ height anomalies. This means that height anomalies are still increasing in the lower stratosphere (Thompson and Wallace, 
1998). If we look at the midlatitude anomalies, especially from the western Asia to eastern American sector, approximately opposite sign of anomalies are found in the $100-\mathrm{hPa}$ temperature field, suggesting a more tropospheric origin of midlatitude anomalies. This result is consistent with the previous analysis that the PEA pattern develops in the troposphere as anomalies in the polar night jet propagate into the troposphere (see Fig. 10 in Kodera and Koide, 1997). On the other hand, if the interaction between the transient eddies is the only mechanism producing the PEA, such a property of a deep polar vortex may be difficult to explain, and the role of planetary waves should be taken into account.

\section{Concluding remarks}

The interannual variabilities in NH winter are examined with a SVD analysis between the winter Z500 field and multi-seasonal joint TS/SST fields. A comprehensive view-point of the $\mathrm{NH}$ winter climate variability related and unrelated to the ENSO cycle is obtained. However, the TNH pattern which also be claimed to be related to the ENSO cycle (Mo and Livesey, 1986) could not be found as an independent mode. So we need to clarify this in the future.

In the present study, we mainly concentrated on the ENSO cycle. However, decadal variability and trends are also considerable in the time series, especially in the TS- 2 mode, while the interannual variability is more prominent in TS-3. These results are consistent with the time-filtered EOF analysis by Tanimoto et al. (1997). The role of atmospheric circulation in decadal change should also be clarified, along with the origin of such long-term variability.

In the present study, we have called the spatial pattern found in Fig. 2a the PEA. This is because the largest amplitudes are found over the polar and Eurasia regions, whereas amplitudes are weak over the Pacific region. However, the PEA pattern found in a GCM simulation with climatological SSTs presents a more zonal structure with comparable amplitude of signal over the Pacific region (Kodera et al., 1996). This suggests that essentially PEA has a hemispheric scale in the troposphere as well as in the stratosphere. Over the Pacific region, however, observed amplitudes are smaller because of the interference with variability forced by changes in SSTs. This implies that we also need to study nonlinear interactions between the modes separated according to the linear operation.

\section{Acknowledgments}

The authors wish to express special thanks to A. Kitoh and H. Nakamura for useful discussions and comments. They are also indebted to Y. Kuroda for his fast SVD code. The authors also express their appreciation to the individuals and organizations who supplied the data sets used in this study: Surface air temperature data compiled by P. D. Jones, and monthly mean 500-hPa geopotential height data analyzed by the National Center for Environmental Prediction (formerly NMC), obtained through the National Center for Atmospheric Research data center. GISST2.2 data and 100-hPa air temperatures were provided by the UK Meteorological Office and the stratosphere research group of the Free University of Berlin. Most of the figures were plotted with the GrADS graphics routine.

\section{References}

Barnston, A.G. and R.E. Livezey, 1987: Classification, seasonality and persistence of low-frequency atmospheric circulation patterns. Mon. Wea. Rev., 115, 1083-1126.

Bjerknes, J., 1969: Atmospheric teleconnections from the equatorial Pacific. Mon. Wea. Rev., 97, 163-172.

Bretherton, C.S., C. Smith and J.M. Wallace, 1992: An intercomparison of methods for finding coupled patterns in climate data. J. Climate, 5, 541-560.

Cheng, X. and T. Dunkerton, 1995: Orthogonal rotation of spatial patterns derived from singular value decomposition analysis. J. Climate, 8, 2631-2643.

Emery, W.J. and K. Hamilton, 1985: Atmospheric forcing of interannual variability in the northeast Pacific Ocean: Connections with El Niño. J. Geophys. Res., 90, 857-868.

Graham, N.E., 1984: Decadal-scale climate variability in the tropical and North Pacific during the 1970s and 1980s: Observations and models results. Clim. Dyn., 10, 135-162.

Halpert, M.S. and C.F. Ropelewski, 1992: Surface temperature patterns associated with the Southern Oscillation. J. Climate, 5, 577-593.

Hoerling, M.P. and A. Kumar, 1997: Why do North American climate anomalies differ from one El Niño to another? Geophys. Res. Lett., 24 1059-1062.

Horel, J.D. and J.M. Wallace, 1981: Planetary-scale atmospheric phenomena associated with the southern oscillation. Mon. Wea. Rev., 109, 813-829.

Kawamura, R., M. Sugi and N. Sato, 1997: Interdecadal and interannual variations over the North Pacific simulated by a set of three climate experiments. $J$. Climate, 10, 2115-2121.

Kodera, K., 1998: Consideration of the origin of the different midlatitude atmospheric responses among El Niño events. J. Meteor. Soc. Japan, 76, 347-361.

Kodera, K., M. Chiba, H. Koide, A. Kitoh and Y. Nikaidou, 1996: Interannual variability of the winter stratosphere and troposphere in the Northern Hemisphere. J. Meteor, Soc. Japan, 74, 365-382.

Koide, H. and K. Kodera, 1997: Characteristics of the recent long-term wintertime variability in the atmosphere and ocean (in Japanese with English abstract and captions). Tenki, 44, 535-550.

Kumar, A. and M.P. Hoerling, 1997: Interpretation and implications of the observed inter-El Niño variability. J. Climate, 10, 83-91. 
Kuroda, Y., 1998: An effective SVD calculation method for climate analysis. J. Meteor. Soc. Japan, 76, 649655.

Lau, N.-C., 1978: On the three-dimensional structure of the observed transient eddy statistics of the Northern Hemisphere wintertime circulation. J. Atmos. Sci., 35, 1900-1923.

Lau, N.-C. and M.J. Nath, 1994: A modeling study of the relative roles of tropical and extratropical SST anomalies in the variability of the global atmosphereocean system. J. Climate, 7, 1184-1207.

Lau, N.-C. and M.J. Nath, 1996: The role of the "atmospheric bridge" in linking tropical Pacific ENSO events to extratropical SST anomalies. J. Climate, $\mathbf{9}$, 2036-2057.

Lin, H. and J. Derome, 1997: On the modification of the high- and low-frequency eddies associated with the PNA anomaly: an observational study. Tellus, 69A, 87-99.

Livezey, R.E. and K.C. Mo, 1987: Tropical-extratropical teleconnections during the Northern Hemisphere winter. Part II: Relationships between monthly mean Northern Hemisphere circulation patterns and proxies for tropical convection. Mon. Wea. Rev., 115, 3115-3132.

Mo, K.C. and R.E. Livezey, 1986: Tropical-extratropical geopotential height teleconnections during the Northern Hemisphere winter. Mon. Wea. Rev., 114, $2488-2515$.

Nitta, T. and S. Yamada, 1989: Recent warming of tropical sea surface temperature and its relationship to the Northern Hemisphere circulation. J. Meteor. Soc. Japan, 67, 375-383.

Ose, T, Y. Song and A. Kitoh, 1997: Sea surface temperature in the South China Sea - an index for the Asian monsoon and ENSO system-. J. Meteor. Soc. Japan, 75, 1091-1107.

Parker, D.E., C.K. Folland and M. Jackson, 1995: Marine surface temperature: Observed variations and data requirements. Clim. Change, 31, 559-600.

Parker, D.E., P.D. Jones, A. Bevan and C.K. Folland, 1994: Interdecadal changes of surface temperature since the late 19th century. J. Geophys. Res., 99, 14373-14399.

Rasmusson, E.M. and T.H Carpenter, 1982: Variations in tropical sea surface temperature and surface wind fields associated with the Southern Oscillation/El Niño. Mon. Wea. Rev., 110, 354-384.

Rogers, J.C. and Mosley-Thompson, E., 1995: Atlantic Arctic cyclones and the mild Siberian winters of the 1980s. Geophys. Res. Lett., 22, 799-802.

Serreze, M., F. Carse and R.G. Barry, 1997: Icelandic low cyclone activity: Climatological features, linkages with the NAO and relationship with recent changes in the Northern Hemisphere circulation. $J$. Climate, 10, 453-464.

Tanimoto, Y., N. Iwasaka and K. Hanawa, 1997: Relationship between sea surface temperature, the atmospheric circulation and air-sea fluxes on multiple time scales. J. Meteor. Soc. Japan, 75, 831-849.

Thompson, D.W.J. and J.M. Wallace, 1998: The Arctic oscillation signature in the wintertime geopotential height and temperature fields. Geophys. Res. Let., 25, 1297-1300.

Ting, M., M.P. Hoerling, T. Xu and A. Kumar, 1996: Northern Hemisphere teleconnection patterns during extreme phases of the zonal-mean circulation. $\mathrm{J}$. Climate, 9, 2614-2633.

Trenberth, K.E. and J.W. Hurrell, 1994: Decadal atmosphere-ocean variations in the Pacific. Clim. Dyn., 9, 303-319.

Wallace, J.M. and D.S. Gutzler, 1981: Teleconnection in the geopotential height field during the Northern Hemisphere winter. Mon. Wea. Rev., 109, 784-812.

Wallace, J.M., C. Smith and C.S. Bretherton, 1992: Singular value decomposition of wintertime sea surface temperature and 500-mb height anomalies. J. Climate, 5, 561-576.

Yukimoto, S., M. Endoh, Y. Kitamura, A. Kitoh, T. Motoi, A. Noda and T. Tokioka, 1996: Interannual and interdecadal variabilities in the Pacific in an MRI coupled GCM. Clim. Dyn., 12, 667-683.

van Loon and J.C. Rogers, 1978: The seesaw in winter temperatures between Greenland and Northern Europe. Part I: General description. Mon. Wea. Rev., 106, 296-310.

Zhang, Y., J.M. Wallace and N. Iwasaka, 1996: Is climate variability over the North Pacific a linear response to ENSO? J. Climate, 9, 1468-1478. 


\section{冬季北半球 $500 \mathrm{hPa}$ 高度と地上温度場の特異值分解解析 \\ 小出 寛・小寺邦彦 \\ (気象研究所)}

最近約 30 年の冬季北半球 $500 \mathrm{hPa}$ 高度とほぼ全球の地上気温/海面水温 (SST) 併合デー夕の特異值分 解 (SVD) 解析を行った。その第 1 モードは極域/ユーラシア (PEA) パターンと呼ばれるもので、局地的 なテレコネクションよりはむしろ半球規模の広がりを持つ大気の内部変動と考えられる。第 1 モードの冬 平均 $500 \mathrm{hPa}$ 高度は、秋から翌春にかけてのユーラシアでの地上気温と密接に関係しており、時系列には 年々から十年の時間スケールの変動が卓越する。また、熱帯のSST 偏差との線形の関係は見られない。第 2 モードと第 3 モードの高度場はそれぞれ太平洋/北アメリカ (PNA) と西太平洋 (WP) 型のテレコネク ションパターンと同定される。これらもまた大気の内部変動と考えられるが、その年々の変動は共に熱帯 太平洋 SST に影響されている。これらの結果を通常行われている $500 \mathrm{hPa}$ 高度と SST のみの SVD 解析 と比較した。高度場とSST の SVD 解析第 1 モードは、ENSO に伴って現れる北半球の循環場の偏差と考 えられ、上記の第 2 モードと第 3 モードの線形結合として表現できる。この結果からエルニーニョごとの 中緯度大気循環の違いは一つには PNA とWP の強さの違い、また一つには ENSO とは独立な PEA の変 動の強度に依存していると解釈できる。さらに大気の变動の鉛直構造を $100 \mathrm{hPa}$ の気温と $500 \mathrm{hPa}$ 高度の SVD 解析を使って調べると、PEA と PNA がそれぞれ第 1 , 第 2 モードとして抽出され、PNA は対流圈 内に限定されているのに対し、PEA はさらに成層圈内にまで伸びている。この違いはそれらが異なるメカ ニズムで励起されていることを示している。 